\title{
TRAPEZOIDAL CURVES \\ IN WIDEBAND PATCH ANTENNA DESIGN
}

\author{
H. Gaha 1, F. Choubani 1, J. David ${ }^{2}$, A. Bouallegue', \\ 1 Syscom Laboratory, ENIT, Tunis, Tunisia, \\ 2 LEN7 Electronic Laboratory, ENSEEIHT, Toulouse, France \\ Hafedh.Gaha@isetcom.rnu.tn
}

DOI: |0.36724/2664-066X-202|-7-3-|7-2|

\begin{abstract}
This paper opens investigations on patch antenna and simple and deformed trapezoidal shape invariants. The simplest and the most compact the antenna is, the most efficient it is and the less it costs. When we aim for a wideband communication, we should design our antennas while taking into account many essential electromagnetic characteristics. This paper studies different patch antenna shapes based on trapezoids. Curves are explored to modify these shapes and to ameliorate the quality of wideband antennas. The moment method is used here as a technique of analyzing (MOM) electric and magnetic fields. Actually, novel invariants in the explored shapes, were underlined in this paper and orient the antenna designer to take care of their dimensions as well as these variables affects closely the bandwidth offered consequently by the designed antenna.
\end{abstract}

KEYWORDS: Trapezoid, Curves, Wideband, Design,

Patch Antenna, Simulation 


\section{Introduction}

In this paper, we try to shape originally our antennas by curved lines. So, we manage these curves as well as we ameliorate antenna reflection coefficient S11. The major aim of this study is to preview the behavior of such antennas and how these non rectilinear shapes are helpful to design wideband antennas. To concretize such idea, we have chosen different shapes as indicated in Fig. 1 and Fig. 2. These antennas are designed then simulated using different design tools such as ADS2003 and ANSOFTEnsemble and our laboratory tools.

We had explored the moment method MOM [1] in order to deduce characteristics of the simulated antennas such as reflection coefficient. We had unified for these antennas the same dielectric: FR4 epoxy $(\mathrm{Er}=4.4)$ with $0.794 \mathrm{~mm}$ as a width (antenna designer could choose this substrate width to get adjusting resonant frequency bands) and used thin copper as conductor to shape the trace of the top and the ground of the antenna. So, simplicity and originality are combined to unveil some secrets of curves in trapezoidal shapes.

Then, we had simulated these different antennas and tried to extract such curves impact on antenna characteristics [2]. First of all, we had distinguished many shape invariants such as radius of the circle in or the circle out (R_out, R_In), L: Length and W: Width of the trapeze, and the couple (LA, WA) as the length and the width of adaptation line fixed respectively to $(6 \mathrm{~mm}, 4 \mathrm{~mm})$. The second step is that we had defined five dimensions and the best four trapezoidal shapes [3].

Then, we had simulated these different antennas and tried to extract such curves impact on antenna characteristics [2]. First of all, we had distinguished many shape invariants such as radius of the circle in or the circle out (R_out, R_In), L: Length and W: Width of the trapeze, and the couple (LA, WA) as the length and the width of adaptation line fixed respectively to $(6 \mathrm{~mm}, 4 \mathrm{~mm})$. The second step is that we had defined five dimensions and the best four trapezoidal shapes [3].

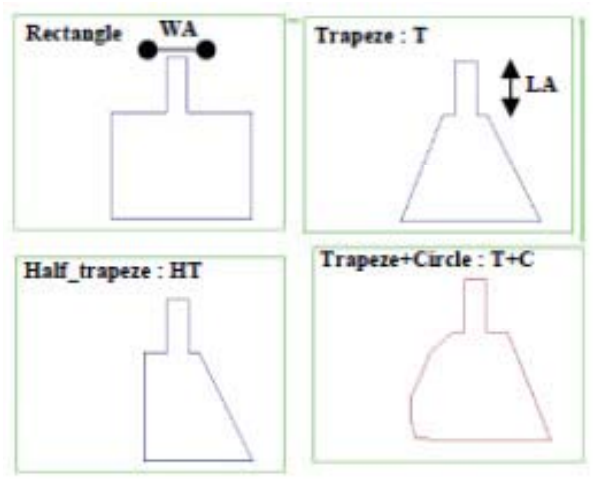

Fig. 1. First set of simulated antennas

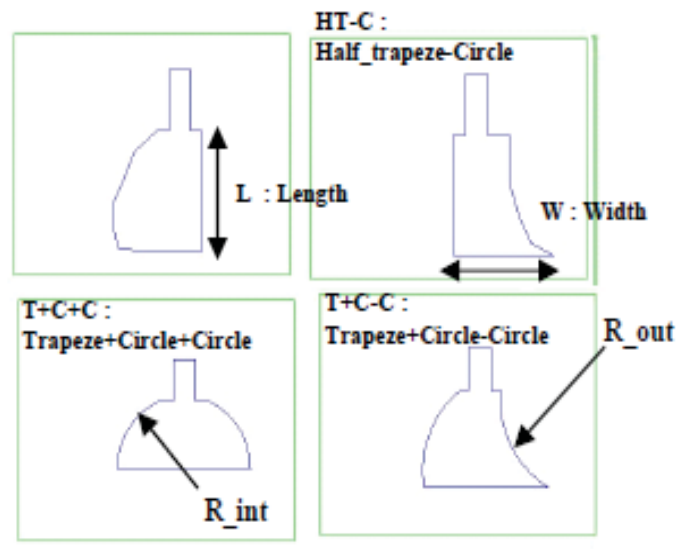

Fig. 2. Second set of simulated antennas

\section{Si ation and results}

Models and mathematical foundations of this paper were detailed and explored in our previous papers $[5,6]$ where we had presented the MOM as the explored method to analyze and calculate antenna characteristics $[2,4]$.

\section{II.1. Shapes' impact [3]}

We represent here $\mathrm{S} 11$ in $\mathrm{dB}$ versus frequency for each couple of antenna in that we compare them by frequency bands from 1 to $20 \mathrm{GHz}$. Then, we deduce the principal conclusions offered by these simulations. Each time we compare two antenna cases, we should precise the concerned frequency interval [4].

The six next figures From Fig. 3 to Fig. 8 represent the different S11 (dB) of each chosen case (we had unified $\mathrm{L}=20 \mathrm{~mm}$ and $\mathrm{W}=26 \mathrm{~mm}$ for all the antennas). Each case is a comparison of two antennas. Fig. 3 illustrates how the rectangle is better than the trapeze in the interval (1.3 to 4.5) GHz. However, Trapeze is considered better in the interval (15 to 17) GHz. All the results are below in table 1 .

Table 1

Shapes and bands resonance

\begin{tabular}{|c|c|c|c|c|c|c|c|}
\hline $\begin{array}{c}\text { Shapes/ } \\
\text { Intervals(GHz) } \\
\text { From } \\
\text { To }\end{array}$ & $\begin{array}{l}\mathrm{I}_{0} \\
\underset{2}{1.4}\end{array}$ & $\begin{array}{l}\mathrm{I}_{1} \\
2.4 \\
4.5\end{array}$ & $\begin{array}{l}I_{2} \\
3.2 \\
4\end{array}$ & $\begin{array}{l}\mathbf{I}_{3} \\
12 \\
15.8\end{array}$ & $\begin{array}{l}\mathbf{I}_{4} \\
12.2 \\
14.8\end{array}$ & \begin{tabular}{l|l}
$I_{5}$ \\
15.3 \\
16.8
\end{tabular} & $\begin{array}{l}\mathrm{I}_{6} \\
16 \\
17.4\end{array}$ \\
\hline $\begin{array}{c}\text { Band Width } \Delta I \\
(\mathrm{GHz})\end{array}$ & 0.6 & 2.1 & 0.8 & 0.8 & 2.6 & 1.5 & 1.4 \\
\hline Rectangle (Fig.3) & - & - & + & - & - & - & - \\
\hline Trapeze (Fig.3,4) & - & - & - & - & - & + & - \\
\hline Trapeze +C-C (Fig. 4,5 ) & + & + & + & - & - & - & + \\
\hline Trapeze +C (Fig 5, 8) & + & + & + & - & - & - & - \\
\hline Trapeze $-\mathrm{C}-\mathrm{C}$ (Fig.6) & + & - & - & + & - & - & - \\
\hline Trapeze +C+C (Fig.6) & + & - & + & - & + & - & - \\
\hline Half Trapeze (Fig.7) & - & - & - & - & - & - & - \\
\hline Half Trapeze +C (Fig.8) & - & - & - & + & - & - & - \\
\hline Half Trapeze $-\mathrm{C}$ (Fig. 7 ) & + & - & + & - & - & - & - \\
\hline
\end{tabular}


Figure 4 demonstrates how adding positive and negative curved surface to a trapeze, affects positively the quality of the antenna even that surface value remains unchaged in the case of a regular trapeze. Fig. 5 illustrates that adding only one positive-curve $(\mathrm{T}+\mathrm{C})$ is better than adding two curves $(\mathrm{T}+\mathrm{C}-\mathrm{C})$ without chaging the surface of the trapeze. In Figure 7, we see how much negativecurve minimises S11 (dB). However, Figure 8 demonstrates how dividing the trapeze by two has deteriorated the quality of the antenna relatively to the entire trapezes. That why we've get rid of the half trapezes HT antennas in the next section of our simulations.

Fig. 6 compares double positive curves $(\mathrm{T}+\mathrm{C}+\mathrm{C})$ and double negative curves (T-C-C), the first is a bit better around 4, 5 and $14 \mathrm{GHz}$. So, adding curves may be a feature that helps the antenna designer to choose the right shape for his application. But with witch dimensions [3]?

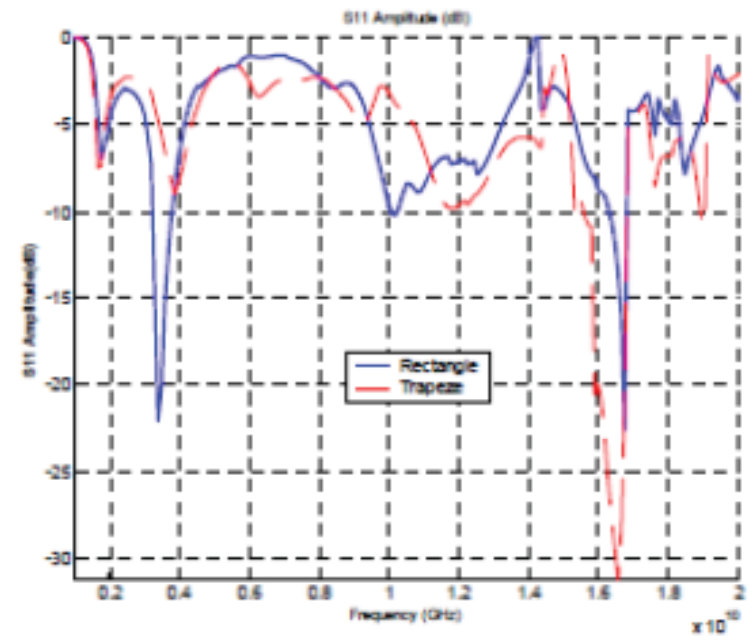

Fig. 3. Reflection coefficient S11 versus frequency Case of Rectangle and Trapeze.

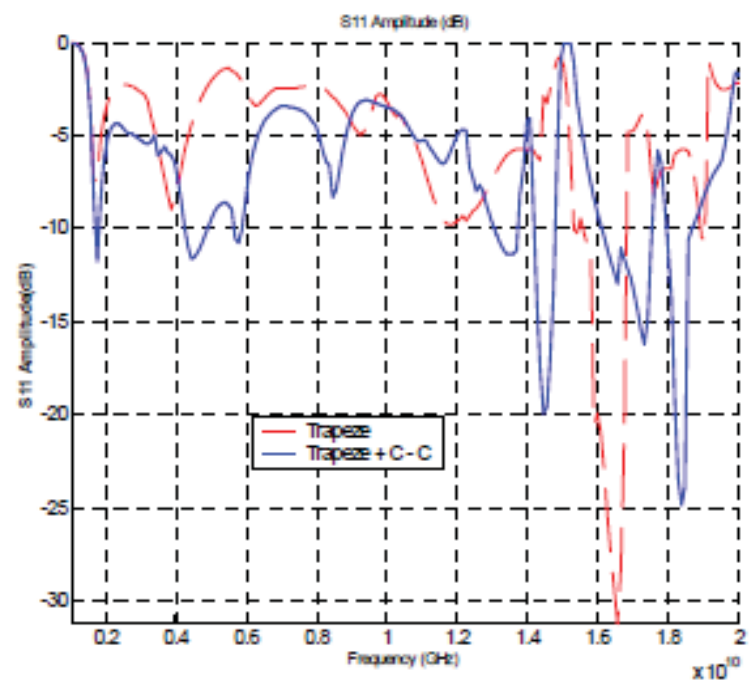

Fig. 4. Reflection coefficient S11 versus frequency Case of Trapeze and $\mathrm{T}+\mathrm{C}-\mathrm{C}$

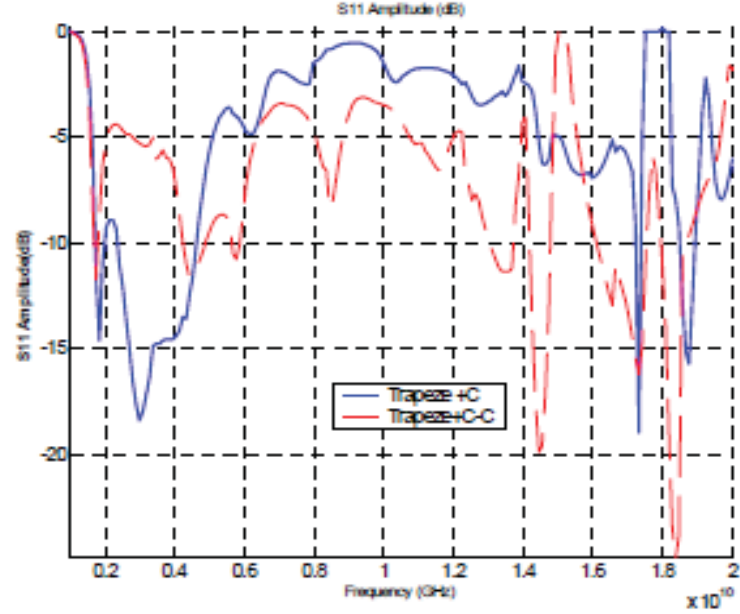

Fig. 5. Reflection coefficient $\mathrm{S} 11$ versus frequency Case of $\mathrm{T}+\mathrm{C}$ and $\mathrm{T}+\mathrm{C}-\mathrm{C}$.

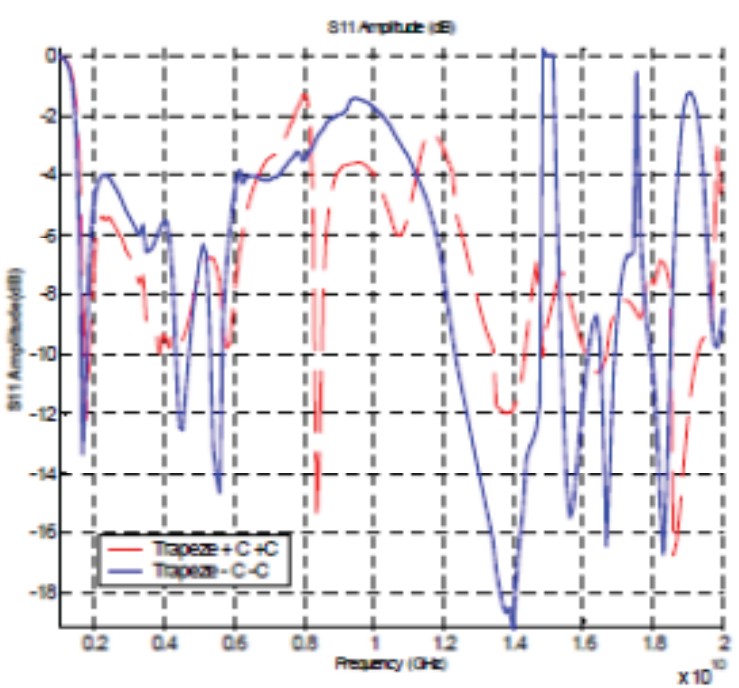

Fig. 6. Reflection coefficient $\mathrm{S} 11$ versus frequency Case of $\mathrm{T}+\mathrm{C}+\mathrm{C}$ and $\mathrm{T}-\mathrm{C}-\mathrm{C}$.

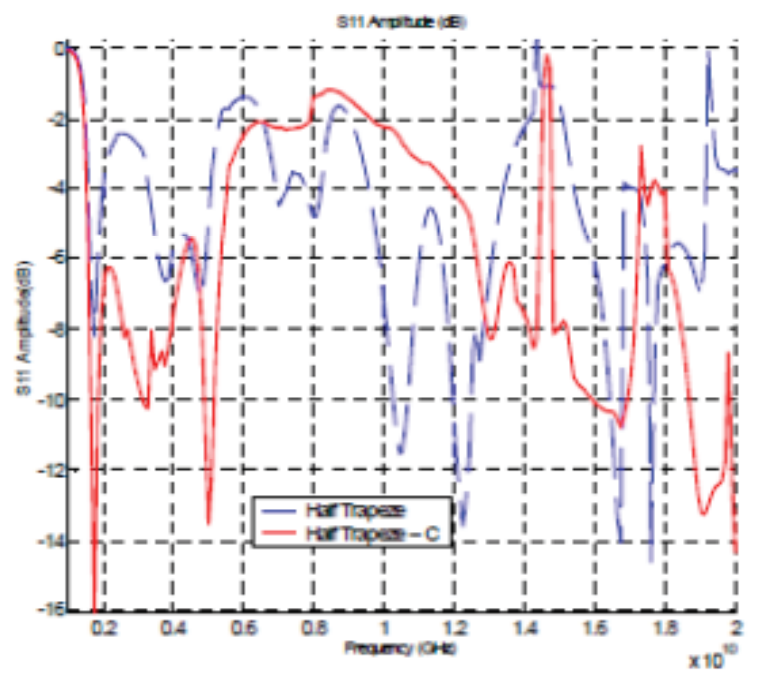

Fig. 7. Reflection coefficient $\mathrm{S} 11$ versus frequency Case of HT and HT-C 


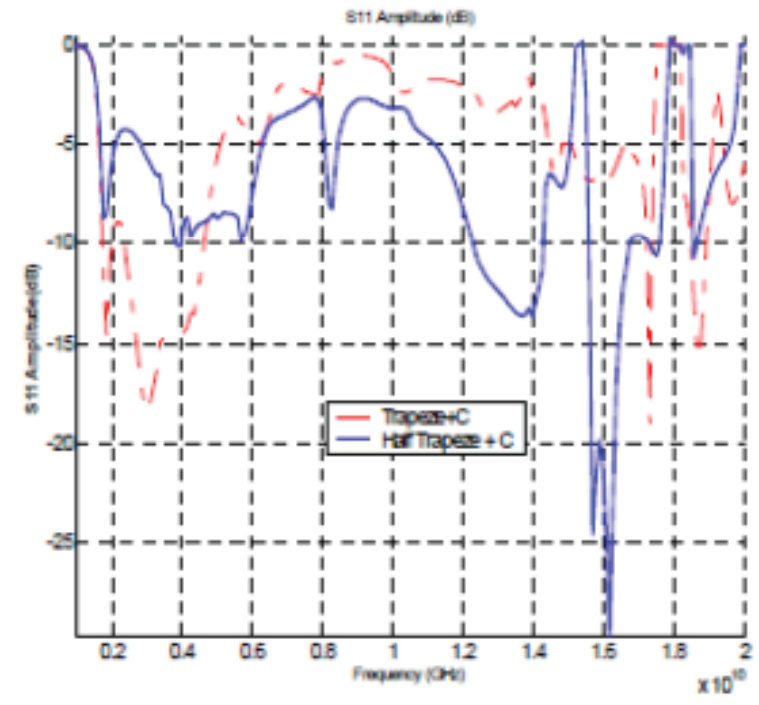

Fig. 8. Reflection coefficient S11 versus frequency Case of $\mathrm{T}+\mathrm{C}$ and $\mathrm{HT}+\mathrm{C}$

\section{II-2. Invariants impact}

The first battery of simulations helped us to select some antennas witch we modified dimensions to see if this latter involves any change in the antenna behaviour [4]. Here are the five dimensions (Dim0, Dim1, Dim2, Dim3, and Dim4) applied to these four shapes [1) $\mathrm{T}+\mathrm{C}, 2$ ) T-C-C, 3) T-C, 4) T+C+C]:

$\begin{array}{lllll}\text { (mm) } & \text { L } & \text { W } & \text { R_in } & \text { R_out } \\ \text { Dim0: } & \mathbf{1 2} & \mathbf{2 4} & \mathbf{1 2} & \mathbf{1 2} \\ \text { Diml: } & \mathbf{2 0} & 35 & \mathbf{2 0} & \mathbf{2 0} \\ \text { Dim2: } & \mathbf{2 0} & \mathbf{4 0} & \mathbf{2 0} & \mathbf{2 0} \\ \text { Dim3: } & \mathbf{2 4} & \mathbf{4 7} & \mathbf{2 4} & \mathbf{2 4} \\ \text { Dim4: } & \mathbf{2 8} & \mathbf{5 2} & 28 & \mathbf{2 8}\end{array}$

Figurs 9-13 are the results of simulations of chosen antennas for several dimensions. Figure 9 illustrates the comparison of the four mentioned antennas in the case of the smallest dimension (Dim0). Two curves added to a Trapeze $(\mathrm{T}+\mathrm{C}+\mathrm{C})$ has the less reflection coefficient $\mathrm{S} 11$ on two widebands around $(4.5 \mathrm{GHz},-20.74 \mathrm{~dB})$ and (6.44GHz,-28.61 dB).

Whenever the dimension increases frequencies are shifted to the left as S11 decreases or may increases too.

Figure 10 unifies the four antennas around $1.9 \pm$ $(0.6,0.2) \mathrm{GHz}$, but illustrates that the negative-curved trapeze $(\mathrm{T}-\mathrm{C})$ resonates also around $8.7 \pm(0.2,0.2) \mathrm{GHz}$.

Figure 11 proves how when dimension decreased (from Dim1 to $\operatorname{Dim} 2),(\mathrm{T}+\mathrm{C})$ and $(\mathrm{T}+\mathrm{C}+\mathrm{C})$ resonate not only around $1.7 \pm(0.1,0.1) \mathrm{GHz}$ but also around $3.4 \pm(0.2,0.2) \mathrm{GHz}$. And this as a shift to the left of S11 and a bifurcation in two bands instead of one. (T-C-C) resonates also around $5.8 \pm(0.2,0.1) \mathrm{GHz}$. (T-C) resonates also around $7.8 \pm(0.2,0.1) \mathrm{GHz}$.

According to Figure 12, $(\mathrm{T}+\mathrm{C})$ and $(\mathrm{T}-\mathrm{C})$ resonates in many widebands. $(\mathrm{T}+\mathrm{C})$ is efficient around $12.9 \pm(0.5,1)$ $\mathrm{GHz}$ and less efficient around $3.7 \pm(0.2,0.2) \mathrm{GHz}$ and $8.6 \pm(0.1,0.1)$ GHz. (T-C) resonates around $5.6 \pm(0.3,0.2) \mathrm{GHz}$ and less efficient around $7.1 \pm(0.2,0.2) \mathrm{GHz}$. Fig.13 shows how $(\mathrm{T}+\mathrm{C}+\mathrm{C})$ is the best antenna in this dimension (Dim 4). In that, it resonates around five bands such as $2.4 \pm(0.3,0.3) \mathrm{GHz}$ and $3.4 \pm(0.1,0.1) \mathrm{GHz}$.

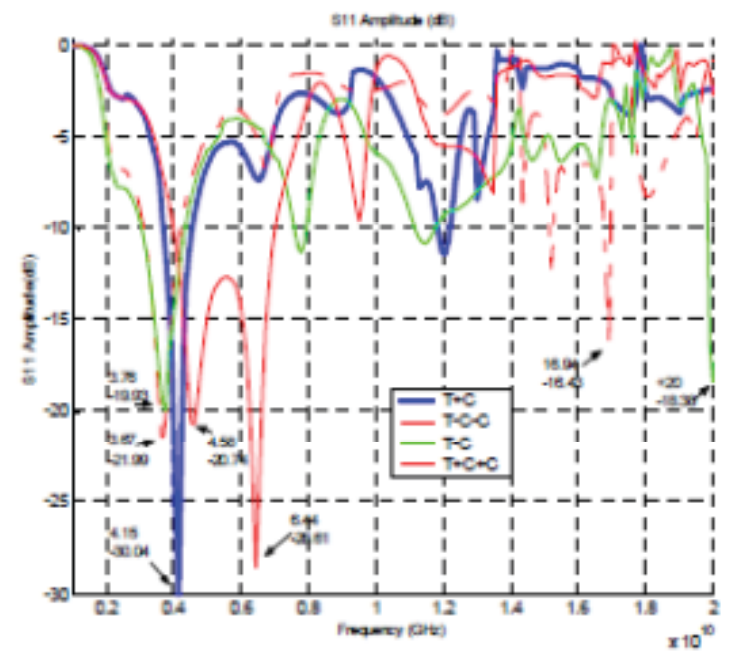

Fig. 9. $\mathrm{T}+\mathrm{C} \& \mathrm{~T}-\mathrm{C}-\mathrm{C} \& \mathrm{~T}-\mathrm{C} \& \mathrm{~T}+\mathrm{C}+\mathrm{C}(\mathrm{Dim} 0)$

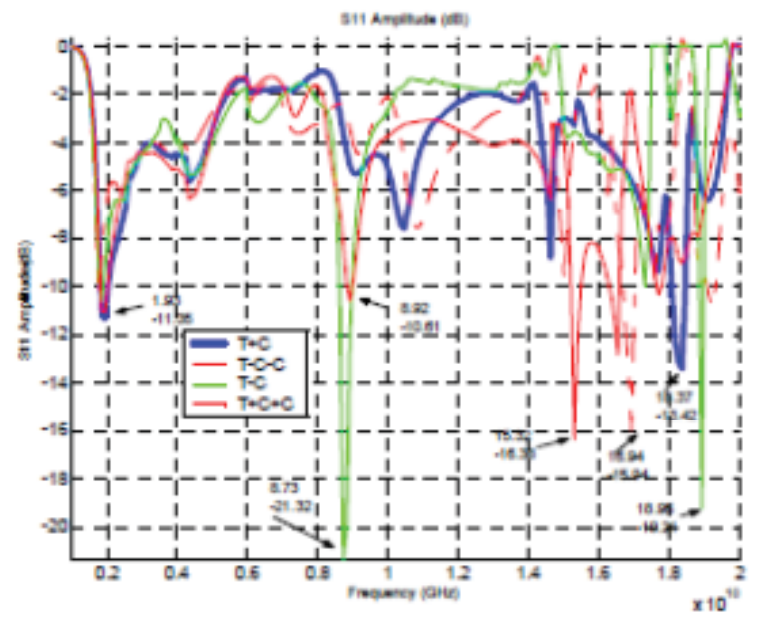

Fig. 10. $T+C \& T-C-C \& T-C \& T+C+C(D i m 1)$

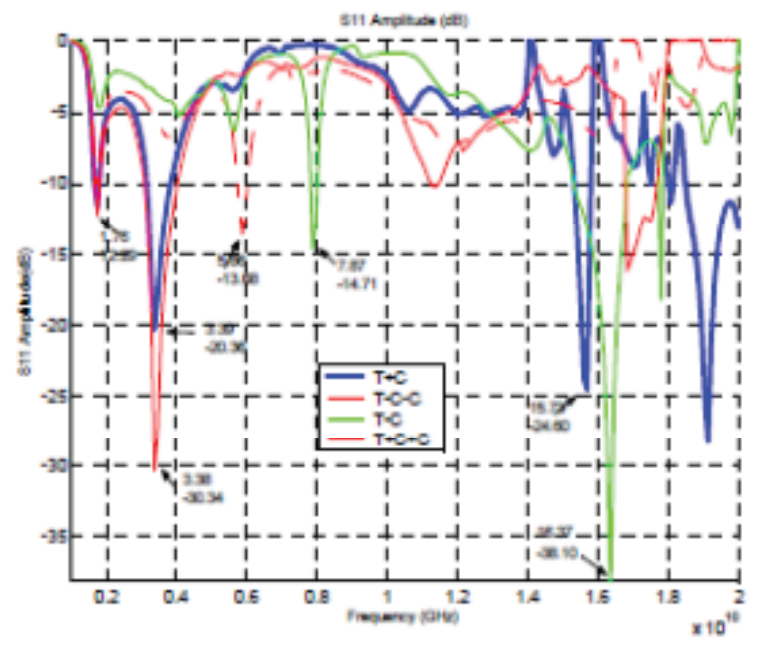

Fig. 11. $T+C \& T-C-C \& T-C \& T+C+C(D i m 2)$ 


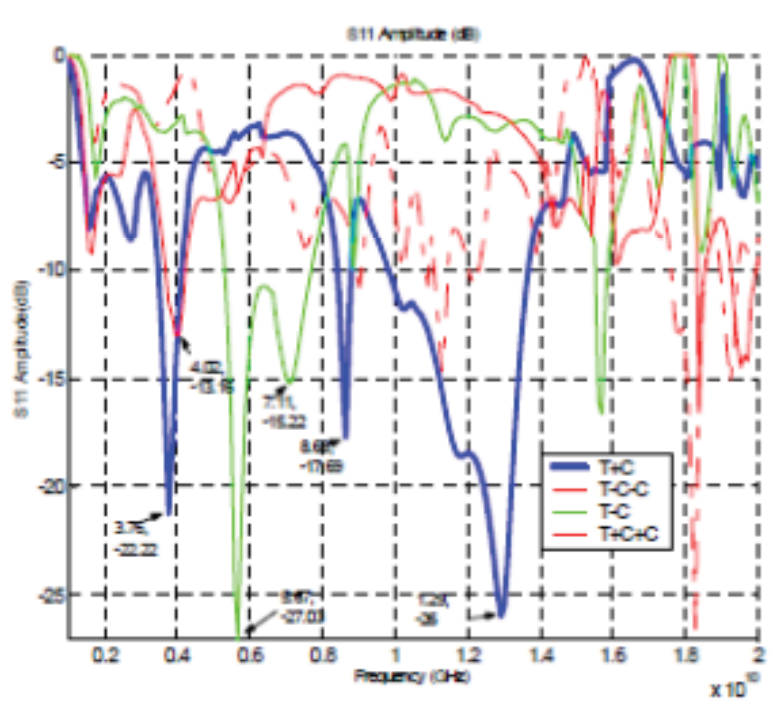

Fig. 12. $T+C \& T-C-C \& T-C \& T+C+C(\operatorname{Dim} 3)$

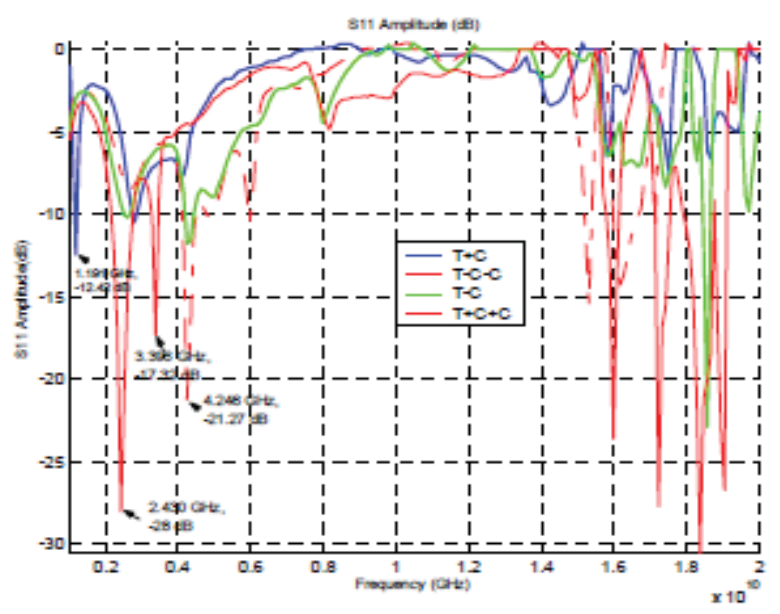

Fig. 13. $T+C \& T-C-C \& T-C \& T+C+C(\operatorname{Dim} 4)$

\section{Conclusion}

In order to design more simple antennas, we have realized two simulation batteries based on trapezoidal shapes combined with curves and applied to five chosen dimensions. Results were verified and commented as well as each studied trapezoidal antenna unveiled its caracteristics. This paper opens an old_new axle research on new simple shapes'antenna. However, we are working also on chaotic shapes.

\section{References}

[1] R. F. Harrington "Field computation by moment methods" 1st, 2nd Piscataway: IEEE Press, 1993.

[2] M.I. Aksoun, R. Mittra, "Choices of expansion and testing functions for the method of moments applied to a class of electromagnetic problem", IEEE transactions on microwave theory and techniques, Vol 41. No3, March 1993.

[3] I. Park, R. Mittra, "Efficient computation for a general microstrip geometry using closed form spatial domain green's function", Electromagnetic Communication Laboratery Report $\mathrm{N}^{\circ}$ 93-1, University of Illinois-February 1993.

[4] M.HELIER, "Technique micro-onde - Structures de guidage, dispositifs passifs et tubes micro-ondes", Edition Ellipses, ISBN: 2-7298-0497-8, 2001.

[5] H. Gaha, F. Choubani, J. David \& A. Bouallegue, "Elaboration d'un Outil de conception des dipôles rayonnants", Conférence Tunisienne de Génie Electrique p368-373 CTGE ' 2004 - Tunis - Tunisia 19, 20 et 21 Février 2004.

[6] H. Gaha, F. Choubani, J. David \& A. Bouallegue, "Conception des antennes imprimées multibandes", La 3ème Conférence Internationale JTEA ' 2004 Hammamet - Tunisia 20-22 Mai 2004. 